\title{
DEZ ANOS DO PROGRAMA DE VOLUNTÁRIOS DO PARQUE NACIONAL DA TIJUCA, RJ
}

\author{
André Bittencourt Amador ${ }^{1}$ \\ Lúcio Meirelles Palma ${ }^{2}$
}

\section{Resumo}

Situado na região metropolitana do Rio de Janeiro o Parque Nacional da Tijuca representa uma opção de lazer para a população da cidade além de possuir um potencial turístico excepcional devido aos seus atributos naturais cênicos que despertam o interesse de visitantes dos diversos estados brasileiros, assim como de turistas estrangeiros. O Parque Nacional da Tijuca tem uma grande necessidade de contar com o apoio da população em atividades de conservação. Devido a sua fragilidade, o parque sofre diversas interferências urbanas como o crescimento desordenado de favelas, e habitações de alta renda em sua área de entorno, o acúmulo de lixo em alguns ambientes naturais, as quedas de balões que causam incêndios, a chuva ácida, o desmatamento, a caça e o ingresso de animais domésticos, além de sofrer impactos ambientais devido à intensa visitação. O programa de voluntariado pode contribuir para a diminuição dos impactos ambientais decorrentes da visitação, ajudando o parque em diversas atividades inclusive na promoção de atividades de educação ambiental e atuando como agentes multiplicadores. Segundo estudos recentes $54 \%$ dos jovens brasileiros gostariam de ser voluntários, porem não encontram oportunidades de trabalho (MMA, 2002). Este projeto abre esta oportunidade convidando a sociedade a refletir e a participar de ações visando à conservação do bem publico comum. O trabalho voluntário no PNT é uma forma de aprimorar o manejo e a gestão da unidade de conservação em atividades significativas, gerando benefícios tanto para o Parque quanto para os voluntários, em uma oportunidade única de interação e reconciliação entre o homem e a natureza.

Palavras chave: Unidades de conservação; educação ambiental; voluntariado

\section{Abstract}

Tijuca National Park (TNP) is located in the metropolitan region of Rio de Janeiro and represents a leisure option for the city's population also has tourism potential due to its exceptional natural attributes of great beauty, attracting the interest of visitors from several states as well as foreign tourists. The TNP has a great need for public support for conservation activities. Due to its fragility, the park suffers several urban interferences as the disorderly growth of slums and high-income housing in its surrounding area, the accumulation of garbage in some natural environments, falls balloons that cause fires, acid rain, deforestation, hunting and entry of domestic animals, in addition to suffering environmental impacts due to intense visitation. The volunteer program can contribute to reducing the environmental impacts of visitation, helping the park in several activities including the promotion of environmental education activities and acting as multipliers. According to recent studies 54\% of Brazilian youngsters would be voluntary, however does not find job opportunities (MMA,

\footnotetext{
1 Voluntário do Parque Nacional da Tijuca, Geógrafo (UFRJ), Mestrado em Geografia (UFF) - E-mail: andrebamador@gmail.com

2 Coordenador do Voluntariado do PNT, Administrador (UCT Petrópolis), Pós-graduação em Educação Ambiental (UERJ). E-mail: luciompalma@yahoo.com.br
} 
2002). This project opens this opportunity inviting society to reflect and participate in actions aimed at conservation of the common public. Volunteer work in the TNP is a way to improve the handling and management of the conservation unit in meaningful activities, generating benefits for both the park and for the volunteers, a unique opportunity for interaction and reconciliation between man and nature.

Keywords: Units conservation; environmental education; volunteer

\section{Introdução}

Voluntário é todo aquele que, por solidariedade, doa seu tempo, trabalho e talento em ações que beneficiam o próximo e melhoram a vida de todos. Qualquer pessoa pode se candidatar a ser voluntário. Não é preciso nenhuma qualificação especial. A doação de tempo, habilidade e talento em beneficio de uma causa sem remuneração tem como retorno o sentimento de inserção no processo transformador daquele que se engaja.

O serviço voluntário em parques em unidades de conservação (UCs) é uma tradição em inúmeros países do mundo. Nos Estados Unidos, o Serviço de Parques Nacionais (National Park Service) conta com um programa de voluntários que gera benefícios mútuos para os parques e para os voluntários. A cada ano mais de 120.000 voluntários doam mais de 4 milhões de horas em serviço nos Parques Nacionais americanos ${ }^{3}$.

Em parques nacionais chilenos, australianos e sul-africanos os voluntários são os principais responsáveis pela manutenção dos sistemas de trilhas e por realizar trabalhos educativos com os visitantes. Na Itália a ONG WWF conta com mais de 35 anos de atividades e grande quantidade de voluntários permanentes e ocasionais para atividades voluntárias diversificadas nos parques e reservas.

No Brasil o trabalho voluntário foi regularizado pela Lei 9.608/98. Segundo esta lei, o serviço voluntário é uma atividade não remunerada, prestada por pessoa física a entidade pública de qualquer natureza, ou a instituição privada sem fins lucrativos que tenha objetivos cívicos, culturais, educacionais, científicos, recreativos ou de assistência social inclusive a mutualidade. O serviço voluntário não gera vínculo empregatício nem obrigação de natureza trabalhista previdenciária ou afim.

O trabalho voluntário em UCs pode ser uma importante ferramenta para a democratização da gestão da unidade, possibilitando um maior envolvimento da população na preservação dos recursos naturais de forma sincera, consciente e espontânea. Através do engajamento dos voluntários garante-se um comprometimento com a causa ambiental e um auxílio importante nos serviços de manutenção da UC, incentivando a proteção das áreas naturais para gerações presentes e futuras.

O Programa de Voluntários do Parque Nacional da Tijuca (PNT) representa a continuidade do programa de Voluntários nos Parques do Brasil desenvolvida pelo Ministério do Meio Ambiente desde 2001. O MMA escolheu o PNT como uma das áreas piloto para a implantação do Programa Nacional de Voluntariado em UCs do IBAMA/MMA.

\footnotetext{
${ }^{3}$ Programa de Voluntariado. Manual do Voluntário do Parque Nacional da Tijuca. Disponível em: < http://www.terrabrasil.org.br/voluntario/manualvolu.pdf $>$.
} 
Anteriormente, várias ações voluntárias já haviam ocorrido no PNT. Em 1999, a União dos Escoteiros do Brasil (UEB) firmou um Termo de Cooperação com o IBAMA visando realizar atividades no PNT. Diversas ONGs e montanhistas de vários centros excursionistas existentes no Rio de Janeiro também realizaram trabalhos voluntários em mutirões de limpeza e manutenção de trilhas.

No início de 2003 o programa de voluntários do PNT foi estruturado e deu início às ações de divulgação, cadastramento de voluntários e além da continuidade das ações de mutirão de voluntários.

Através da análise da demanda para o trabalho voluntário, foi realizada uma priorização das atividades voluntárias no parque. As atividades priorizadas para o início do trabalho voluntário no PNT foram: O monitoramento, recuperação e manutenção de trilhas; As atividades de atendimento ao público e monitoramento dos visitantes; o reflorestamento de áreas degradadas; o levantamento da fauna; e a realização de atividades administrativas/biblioteca. Posteriormente foi incluída a realização de mutirões de limpeza de áreas do parque também como atividade priorizada.

Como material de apoio para as atividades dos voluntários foram elaborados: um folder sobre a conduta consciente em ambientes naturais, cartazes incentivando o cadastramento de novos voluntários, camisetas para identificação dos voluntários e um manual do voluntário com informações sobre o PNT e o trabalho voluntário.

Em 2002 foi assinado o Decreto do Ministério do Meio Ambiente $n^{\circ}$ 4.519, que regulamentou o serviço voluntário em UCs federais. Em 2005 foi publicada a Portaria $\mathrm{n}^{\circ} 19$ do Ministério do Meio Ambiente, que dispôs sobre a criação de Programa de Voluntariado em UCs Federais. Mais recentemente foi publicada uma INSTRUÇÃO NORMATIVA do ICMBio 03/2009 Estabelecendo as diretrizes, normas e procedimentos para implementação do Programa de Voluntariado no âmbito do ICMBio.

O Programa de Voluntários no PNT promove diversas atividades definidas por um planejamento técnico do parque, são elas: mutirão voluntário, manutenção de trilhas, manejo da flora, patrulha ambiental e atendimento ao publico.

A proposta desse Programa de Voluntários é, de forma mais ampla, atrair a população para um trabalho integrado de gestão, tendo como finalidade levá-lo a uma tomada de consciência de que o parque é um bem público, a serviço e a cuidados de todos. A concepção disso envolve um processo de educação ambiental a ser expandido para todos os visitantes, fazendo com que esses percebam que a conduta consciente no Parque, já é por si só, um ato voluntário em defesa dos recursos naturais. A prática da ação voluntária não se resume, portanto, a membros cadastrados.

Uma ideia central do projeto é o fortalecimento da gestão e do manejo do PNT através do trabalho voluntário, segundo a ideologia inspiradora de gestão participativa do Sistema Nacional de Unidades de Conservação (SNUC). De acordo com a Lei do SNUC (N. ${ }^{\circ}$ 9.985/2000) em seu Artigo $5^{\circ}$ “O SNUC será regido por diretrizes que: (..) III - assegurem a 
participação efetiva das populações locais na criação, implantação e gestão das unidades de conservação"; (...).

O estímulo ao trabalho voluntário está de acordo com essa ideia e, desde o surgimento dos parques, vem sendo utilizado de forma muito satisfatória em outros países, dando origem, inclusive, a organizações internacionais de voluntários de UCs. Essa manifestação demonstra a influência e a importância dessa atividade no cenário ambiental em âmbito nacional e internacional.

O Programa prevê atividades permanentes, de responsabilidade dos voluntários cadastrados, indo ao encontro das necessidades de uma instituição que tem como objetivo maior garantir a manutenção dos recursos naturais essenciais à vida da humanidade.

O objetivo principal é contribuir para a conservação do PNT, com ênfase na melhoria da qualidade de vida daqueles que residem no seu entorno e na conscientização da população em geral para a preservação ambiental da Mata Atlântica do local, além de chamar atenção para seu potencial turístico e de entretenimento.

Também são objetivos: desenvolver através de ações voluntárias uma educação ambiental voltada para a conscientização e conservação do parque; incentivar e desenvolver através do voluntariado uma territorialidade positiva entre o visitante e a UC; consolidar a participação da sociedade através do trabalho voluntário UCs; criar oportunidades para o exercício da cidadania através do voluntariado no PNT; promover uma conscientização participativa junto aos voluntários, visitantes e moradores do entorno do parque.

O Programa de Voluntários do PNT tem objetivos específicos: realizar mutirões de limpeza e educação ambiental; realizar o monitoramento, a recuperação e a manutenção das trilhas do PNT; aprimorar as atividades de atendimento ao público e monitoramento dos visitantes; promover reflorestamento de áreas degradadas; realizar manejo de flora - controle de espécies exóticas; apoiar atividades administrativas; contatar ONG`s voluntárias (Escoteiros, Montanhistas, etc.) para realização de atividades através de parcerias e convênios; desenvolver convênios com universidades para a realização de estágios de pesquisa; realizar intercâmbio com voluntários estrangeiros com experiência em trabalhos em áreas protegidas de outros países.

No presente artigo serão apresentadas informações sobre as experiências de trabalho adquiridas pelo Programa de Voluntariado do PNT ao longo dos dez anos de sua existência, suas metodologias de atuação e os resultados concretos percebidos a partir das suas atividades.

\section{Metodologia de Trabalho do Programa de Voluntariado do PNT}

Foi adotada como referência a metodologia contida no manual de "Planejamento e Operação de Programas de Voluntários em Unidades de Conservação" (MMA, 2002). Trata de uma excelente publicação que atende aos objetivos propostos para a operação do Programa de Voluntariado do PNT e apresenta passos metodológicos bem detalhados e informações relevantes, para a eficiência e sucesso do programa de voluntários. 
Dentre outros aspectos, o manual estabelece orientações para as etapas de: cadastramento, entrevista, preenchimento de termo de adesão, orientação, treinamento, supervisão, avaliação e reconhecimento do voluntário.

O ponto de partida do programa é a realização de um evento de Planejamento do Voluntariado com a equipe do parque, onde são realizadas oficinas, palestras e dinâmicas de trabalhos, tendo como metodologia básica o manual supracitado. Neste evento procura-se realizar um planejamento participativo e detalhado do programa de voluntariado na respectiva UC. Após o planejamento, passa-se à etapa de divulgação do programa de voluntariado com cartazes, distribuição de folders aos visitantes, convites pela internet, participação em eventos e anúncios em jornais universitários. O cadastramento de voluntários avulsos é feito no Centro de Visitantes e através do site na Internet. Os voluntários cadastrados são contatados para entrevista, para depois serem treinados e entrarem em atividade nas áreas priorizadas, levando em conta seus interesses e habilidades.

Todos os voluntários e entidades podem participar, cada um dentro das suas possibilidades, tendo a autorização e orientação técnica do parque para o desenvolvimento das atividades em consonância com as Leis e Regulamentos dos Parques Nacionais. A capacitação dos voluntários pode ser realizada em duas etapas, sendo a primeira mais geral para os voluntários avulsos e eventuais, através da Oficina de Voluntários. Esta oficina servirá para preparar e orientar os voluntários do Programa. A Oficina aborda aspectos gerais necessários a qualquer voluntário tais como: informações básicas sobre o PNT (área, regulamento, estrutura administrativa, etc) e sobre o Programa de Voluntários (técnicas, orientações, possibilidades de atuação, etc.). A segunda etapa da capacitação é a orientação técnica específica do voluntário e esta capacitação pode ser realizada nas semanas após a oficina.

As atividades são desenvolvidas seguindo o planejamento elaborado por profissionais do parque e representantes do ICMBio, tendo como metodologia básica o manual do MMA (2002). Todas as atividades são acompanhadas de um coordenador de voluntários do parque. O coordenador orienta o participante quanto ao local e o trabalho a ser desenvolvido, após a atividade, produzindo posteriormente um relatório contendo informações do trabalho executado.

Através da análise de demanda de trabalho voluntário, chegou-se à seguinte seleção de atividades no parque:

Mutirão Voluntário do PNT - É a atividade central do programa. No mutirão, o parque pode experimentar um pouco de democracia direta na gestão e no manejo, através da participação dos voluntários na proteção do meio ambiente. Em geral, são realizadas coletas de lixo em ambientes naturais, atividades de manutenção das trilhas e distribuição de folders da conduta consciente com conversa com os visitantes.

A frequência do mutirão é mensal e a atividade é sempre realizada nos finais de semana (sábados ou domingos). Em geral, escolhe-se uma data relacionada ao calendário ecológico. A divulgação para os voluntários é feita com antecedência (data, hora, ponto de 
encontro e programação do mutirão), principalmente por endereço eletrônico, através de mala direta dos voluntários cadastrados no programa, e por telefone.

No dia do Mutirão, na hora e local combinados, o grupo se reúne em uma grande roda, onde é feita uma saudação geral do parque agradecendo a participação de todos. Os voluntários se apresentam e recebem uma orientação geral dos trabalhos que serão realizados. Posteriormente, os voluntários são divididos em grupos, cada um deles acompanhado de coordenador (funcionário do Parque ou voluntário com experiência) que irá supervisionar e orientar o trabalho dos voluntários.

Quando possível, é disponibilizado lanche aos participantes e transporte até o início da trilha a ser trabalhada, também são fornecidas ferramentas, luvas, sacos de lixo e kit de primeiros socorros. Em geral essa atividade tem repercussão de mídia, o que acaba reforçando a ideia da educação ambiental de difundir a importância de todos terem uma atitude de zelo e respeito com o parque e o meio ambiente.

Manutenção de trilhas - As atividades de manutenção de trilhas têm sido realizadas nos mutirões tendo várias tarefas: o fechamento de atalhos, a construção de degraus, a abertura de drenos de água para diminuição da erosão, a reposição de sinalização, o corte de mato ou de árvores caídas sobre a trilha, a coleta de lixo e o preenchimento de ficha de monitoramento da trilha.

O Coordenador do programa de voluntariado deve ser alguém da equipe permanente da UC, pois atua como elemento de ligação entre os voluntários e a equipe da instituição. Deve atuar em parceria com supervisores de atividades sendo o responsável pelo gerenciamento e operacionalização do programa na UC. Pode contar com estagiários e voluntários coordenadores.

Os Parceiros do programa de voluntariado do PNT contribuem e dão apoio de diferentes formas: cedendo voluntários, na divulgação e reconhecimento do programa e/ou contribuindo com lanche, transporte, equipamentos e uniformes. É importante estar aberto para receber a contribuição de todos, pois existe uma tendência de que, conforme o programa se amplie, outros apoiadores vão surgindo para contribuir nas ações dos voluntários no PNT. Para o sucesso deste planejamento, é imprescindível que as ONGs parceiras, voluntários avulsos e eventuais se sintam partes integrantes e estejam motivados com o Programa. Assegurar os recursos necessários, permitir alterações no planejamento a partir da resposta dos voluntários e reconhecer suas ações, são cuidados importantes para o sucesso e perenidade do projeto.

Avaliações frequentes e informais pelo supervisor e pelo voluntário podem contribuir para o aprimoramento do Programa. Os supervisores devem conduzir entrevista informal com cada voluntário novo, após o primeiro e sexto mês. Ao término de seu serviço, o voluntário deverá receber uma avaliação por escrito do seu supervisor. As avaliações podem ser breves e práticas, elas fornecem subsídios para que se decida quanto à continuidade ou não dos serviços de um voluntário. Os voluntários também devem avaliar o programa e podem apontar aspectos que necessitem de melhoria (MMA, 2002). 
Os coordenadores podem preencher ficha de avaliação dos voluntários e devem conduzir entrevista informal com cada voluntário após três meses de atividade. $\mathrm{O}$ reconhecimento incentiva o voluntário a continuar trabalhando e é essencial para mantê-lo. $\mathrm{O}$ trabalho da equipe remunerada que atua com o voluntariado também deve ser reconhecido, a fim de manter o apoio e o entusiasmo do programa.

\section{Resultados dos Dez Anos do Programa de Voluntariado}

Depois de dez anos das atividades voluntárias no PNT, percebeu-se nitidamente a importância que teve como multiplicador efetivo da consciência ecológica e agente de mobilização da sociedade. A manutenção deste programa tornou-se essencial para a conservação do parque. $\mathrm{O}$ projeto tem tido uma grande repercussão na sociedade devido à grande participação da mídia como divulgadora dos mutirões e atividades dos voluntários através de reportagens de jornais e televisão. As matérias em jornais e TV reforçam a ideia da população cuidar do meio ambiente e funciona como uma educação ambiental pelo gesto, individual e coletivo, de cuidado com o parque.

Essas estratégias de sensibilização da coletividade, conscientização pública e divulgação do programa e dos voluntários através da mídia, está em consonância com o artigo 225 da Constituição Federal e com o artigo 13 da Lei da Educação Ambiental. Segundo a Constituição Federal (Brasil, 1988) em seu Artigo 225. "Todos têm direito ao meio ambiente ecologicamente equilibrado, bem de uso comum do povo e essencial à sadia qualidade de vida, impondo-se ao Poder Público e à coletividade o dever de defendê-lo e preservá-lo para as presentes e futuras gerações". $1^{\circ}$ - Para assegurar a efetividade desse direito, incumbe ao Poder Público: VI - promover a educação ambiental em todos os níveis de ensino e a conscientização pública para a preservação do meio ambiente;

Segundo a Lei 9.795/99, artigo. 13, “Entendem-se por educação ambiental não-formal as ações e práticas educativas voltadas à sensibilização da coletividade sobre as questões ambientais e à sua organização e participação na defesa da qualidade do meio ambiente". Parágrafo único: “O Poder Público, em níveis federal, estadual e municipal, incentivará: I - a difusão, por intermédio dos meios de comunicação de massa, em espaços nobres, de programas e campanhas educativas, e de informações acerca de temas relacionados ao meio ambiente; IV - a sensibilização da sociedade para a importância das unidades de conservação."

O Programa de Voluntários também está em consonância com os preceitos da Educação no Processo de Gestão Ambiental que vem sendo construída pelos educadores do IBAMA e ICMBio, que objetiva o desenvolvimento de capacidades, visando a participação individual e coletiva na gestão do uso dos recursos ambientais e na concepção e aplicação de decisões que afetem a qualidade do meio ambiente. Propõe um maior controle social no processo decisório sobre a destinação dos recursos ambientais na sociedade (Quintas, 2003).

A atividade voluntária é importante, sobretudo para que as pessoas desenvolvam a consciência de que o parque é um bem público, portanto pertence a todos e todos devem cuidar do seu patrimônio. Nesse aspecto a ação voluntária está intimamente associada à educação ambiental e a consequente "conduta consciente em ambientes naturais". Um dos 
eixos norteadores do Programa de Voluntariado do PNT é de que se o visitante agir com uma conduta consciente, em termos práticos, ele já é um voluntário, independente de se cadastrar e assinar o termo de adesão, ou seja, a sua ação já é voluntária.

O Programa de Voluntários do Parque Nacional da Tijuca já está sendo implementado a cerca de dez anos com grande sucesso no Rio de Janeiro em termos de participação de voluntários, adesão de importantes apoios (órgãos públicos, ONG`s e empresas) e conscientização pública através dos meios de comunicação. Nesse período foi contabilizada a participação de mais de 10.000 voluntários realizando cerca de 30.000 horas de trabalho em atividades de manutenção de trilhas, mutirões de limpeza, patrulha ambiental, manejo de flora e atendimento ao público.

Atualmente o Programa conta com cerca de 1.500 voluntários cadastrados (a maioria constituída por moradores do entorno do PNT) e tem apoio de importantes parceiros como: ICMBio, Sociedades de Amigos do Parque Nacional da Tijuca, Prefeitura do Rio de Janeiro, União dos Escoteiros do Brasil, União de Caminhantes e Escaladores Rio de Janeiro (UNICERJ), DEUTER, APPAI, TRILHAS QUASE SECRETAS.

Pode-se concluir que este projeto está sendo bem sucedido em vários aspectos, dentre eles: a efetiva participação cidadã de voluntários (moradores do entorno) em atividades de conservação e conscientização do PNT; a parceria com importantes órgãos públicos, ONGs e empresas patrocinadoras; além de continuar tendo uma boa repercussão nos meios de comunicação através de várias matérias e reportagens na TV e jornais. Destaca-se que as atividades do programa de voluntários têm contribuído para o encaminhamento de estratégias de solução para uma série de problemas e conflitos ambientais.

O trabalho tem possibilitado aos voluntários a oportunidade de ajudar a preservar o ambiente, de promover encontros e construir novas amizades, de obter novos conhecimentos, de expressar seus talentos e de desenvolver novas competências e habilidades. Em relação aos dois últimos aspectos, isto tem contribuído para que alguns voluntários sejam contratados para fazer parte do quadro de funcionários do PARNA da Tijuca. Além disso, consolidar e manter o programa de voluntariado é um estímulo à participação da sociedade nas diversas ações de gestão e manejo do PNT (FRANZ; FREITAS, 2009).

\section{Conclusões}

O Programa de Voluntários do PNT se estruturou desde 2003, quando foi aberto o cadastramento e criado um site na Internet, atualmente o PNT conta com cerca de 1.500 voluntários cadastrados e tem agregado uma série de apoios de diversas entidades. Já foram realizados 97 mutirões voluntários, mobilizando em média 50 voluntários por mutirão perfazendo mais de 30.000 horas de trabalho voluntário.

É importante que a experiência bem sucedida do PNT se espalhe para outras UCs pelo Brasil. Com iniciativas de mutirões de limpeza e manutenção de trilhas se multiplicando, cada vez mais pessoas se juntam à causa do meio ambiente e passam a exercer sua cidadania ambiental e a cuidar do seu parque. 
Acredita-se nessa força transformadora do voluntariado, sem esperar passivamente pelas atitudes dos outros e dos governos. O voluntariado é uma forma de sair da passividade, de educar e cobrar com seu ato e gesto de união nos mutirões voluntários em uma soma de esforços coletiva em prol de um bem público.

Para aqueles que se propõem criar um grupo de voluntários, que sejam buscadas orientações de ONGs e entidades que já têm experiência no setor, assim como a leitura das publicações pertinentes, incluindo o suporte legal das leis e instruções relacionadas ao assunto. A busca de parcerias, a criação de cadastros de voluntários e o estabelecimento de rotinas de atividades com certa frequência, são diretrizes importantes.

Para a continuidade e fortalecimento dos programas de voluntariados nas UCs é importante que os gestores do ICMBio e INEA valorizem mais este tipo de trabalho, incorporando o voluntariado nas práticas de manejo e gestão dos parques e demais áreas protegidas. A criação dos Conselhos de UCs e os Programas de Voluntariado são importantes ferramentas para a democratização da sua gestão.

\section{Agradecimentos}

A todos os voluntários e grupos apoiadores pelo esforço e dedicação nas atividades e mutirões do PNT. A administração do PNT (ICMBio) pelo apoio e continuidade do Programa de Voluntários.

\section{Bibliografia}

AMADOR A.B. Manual do Voluntário do Parque Nacional da Tijuca: educação por Natureza. 2003. 25 p.

AMADOR, A.B. Qualidade das águas do Alto Rio Macaé; Nova Friburgo. 2003. 150 p. Rio de Janeiro. Dissertação (Mestrado em Geografia)- Universidade Federal Fluminense, Niterói, 2003. 150 p

AMADOR, E.S. Bacia da Baía de Guanabara Características Geoambientais: Formação e Ecossistemas. Rio de Janeiro: Interciência, 2012.

Baía de Guanabara Ocupação Histórica e Avaliacão Ambiental. Rio de Janeiro: Interciência, 2013.

BANDEIRA, C. M. Parque Nacional da Tijuca. São Paulo: Makron Books, 1993. 169p.

COELHO NETTO, A.L. O Geoecossistema da Floresta da Tijuca. In: ABREU, M. de A. (Org.). Natureza e Sociedade no Rio de Janeiro. Rio de janeiro, 1992. (Biblioteca Carioca).

DIAS, G.F. Educação Ambiental. Princípios e práticas. São Paulo: Ed. Gaia, 1983.

DIAS, G. F. Manual do Voluntário: Orientações para o corpo de voluntários do Parque Nacional de Brasília (água mineral).Brasília, 2002. 60 p.

IBAMA. Programa Nacional de Educação Ambiental: Proposta Técnica. Brasília: IBAMA/ Doc. Mimeo. 1994. 
MINISTÉRO DO MEIO AMBIENTE. IBAMA. O Parque é seu: Como conhecer, usar e cuidar do Parque Nacional da Tijuca. Rio de Janeiro: IBAMA/CECIP, 1998. 32 p.

FRANZ, B.; FREITAS, M.A.V. Contribuições do trabalho voluntário para da preservação ambiental do Parque Nacional da Tijuca, Rio de Janeiro. In: SEABRA, G.F. ; MENDONÇA, I. T. L. (Org.). Educação ambiental para a sociedade sustentável e saúde global. João Pessoa: Editora Universitária da UFPB, 2009. v. 2, p. 234-240.

MENEZES, P. C. Trilhas do Rio. Rio de Janeiro: Salamandra, 1996. 176 p.

MINISTÉRIO DO MEIO AMBIENTE. Planejamento e Operação de Programas de Voluntariado em Unidades de Conservação. Brasília: MMA/SBF/DAP, 2002. 44 p.

PLANO DE MANEJO para o Parque Nacional da Tijuca. Brasília: ICMBio/ Instituto Chico Mendes de Conservação da Biodiversidade. Brasília: Ministério do Meio Ambiente, 2008.

QUINTAS, J. S. Educação no processo de gestão ambiental: uma proposta de educação ambiental transformadora e emancipatória. Brasília: IBAMA/ Doc. Mimeo, 2003.

RIO VOLUNTÁRIO. Manual da Instituição: trabalhando com voluntariado. Brasília: Secretaria de Estado de Assistência Social, 2001. 30 p.

SANT`ANNA, A.B.C. Caracterização do uso público nas trilhas da Floresta da Tijuca (Parque Nacional da Tijuca). 2000. Dissertação (Mestrado)- Universidade Estácio de Sá, Rio de Janeiro, 2000.

USA National Park Service. Volunteers in parks. Washington, DC, 1994. 